\begin{tabular}{l|l} 
& $\begin{array}{l}\text { Eastern } \\
\text { European } \\
\text { Countryside }\end{array}$ \\
\hline DO.1515/eec-2015-0001 & $21^{\prime} 2015$
\end{tabular}

Andrzej Kaleta

\title{
E-learning as a Diffusion of Innovation in the Rural Areas of the European Union ${ }^{1}$
}

\begin{abstract}
Early observations show that the introduction of e-learning to the rural areas of the EU has brought fewer advantages than had initially been expected. The results of the international research - interpreted by the means of the sociological theory of diffusion - indicate that the economic profitability does not have much influence on the pace of disseminating of that innovation; since, the rural inhabitants - both those following the e-learning courses as well as those who have not yet done so largely feel that that type of education has the variety of advantages including the lowering of its costs. It seems that its social profitability has the crucial influence on the poor dissemination of this new form of teaching and learning. E-learning has not yet found its niche in the value systems or educational experiences of the Europe's rural populations, since - rather like the other forms of education - it does not automatically improve the capability of coping with the current day-today problems. The better adaptation to the needs of the rural inhabitants through the perception of various types of the deficits hindering the usage of this type of education is intended by the so-called innovative e-learning, implementing new and generally innovative solutions to the pedagogical, technological and

1 The article entitled 'E-learning jako dyfuzja innowacji na obszarach wiejskich Unii Europejskiej' ['E-learning as a diffusion of innovation in the rural areas of the European Union'] has been published in Polish in: Kultura i Edukacja [Culture and Education], vol 2’2014, pp. 134-145.
\end{abstract}


organisational fields, which overcome existing limitations through the greater flexibility of the ways of the potential participants' accessing e-learning proposals as well as the greater adaptation to the individual needs.

Keywords: education, rural areas, e-learning, innovations, diffusion of innovation

In all the countries of the European Union ${ }^{2}$, there is a growing awareness of the role of good education as a condition for success in life. A growing number of rural inhabitants and those living in small towns are convinced that learning is both necessary and worthwhile. ${ }^{3}$ Achieving such educational aspirations remains an unsolved problem. In Europe, as in all the other continents of the world, there is still diversification in the educational and

${ }^{2}$ Regardless of the accepted criteria, rural areas cover over $90 \%$ of the surface of the EU and are inhabited by about $60 \%$ of its citizens. Among the 28 member countries some are more rural, other more urbanised. The former include Bulgaria, Denmark, Ireland, Hungary, Romania, Slovakia, Finland and Sweden with rural areas occupying over 95\% of their territory. On the other hand, we find only Belgium and Holland with rural areas no larger than $70 \%$ of the surface and Malta, which according to the accepted definition of rural areas, lacks this type of territory. The number of people living in the countryside and small towns in the EU's countries vary. $80 \%$ of the population of Bulgaria, Hungary, Romania, Slovenia and Slovakia is rural; whereas, only 30\% of the population of Holland and Great Britain is rural. See data: http://ec.europa.eu/agriculture/agrista/rurdev2010/ RD - Report 2010 Summary Tables.xls: tables 2.2.1.2.1 and 2.2.1.2.2.

3 A growing number of Polish rural inhabitants are demanding good education, although their educational aspirations continue to be lower than those of the urban inhabitants. It emerges from Joanna Nikorowicz's report that in $200551 \%$ of the Polish rural inhabitants aged $20-24$ (a rise of $12 \%$ in relation to 2003 ) and $9 \%$ of the rural inhabitants aged 25-29 expressed the wish to continue learning. However, the 20-24-year-olds living in medium and large towns expressed that wish as follows - 46\% in 2003 and 54\% in 2005 and respectively $61 \%$ and $70 \%$. In the 25-29 year-old group the disproportions were greater (9\% - countryside and 25\% - towns). See: J. Nikorowicz, http://www.rowniwpracy. gov.pl/forum/t,1613.html. 
hence life opportunities of both the children and youth in the primary and secondary education ${ }^{4}$, as well as the adults in Lifelong Learning. ${ }^{5}$

Great hopes - revealed in many papers ${ }^{6}$ - connected with the positive influence of e-learning on the improvement and democratisation of the access to knowledge in the rural areas of Europe ${ }^{7}$ are, however, toned

${ }^{4}$ Europe's rural inhabitants have a relatively high level of schooling. Almost $72 \%$ of adults, i.e. people aged 25-64, have education above primary education. However, in all the EU's countries this is lower than that of the urban population $(76.3 \%)$ and the population of the whole united Europe (73.3\%). The educational standard of the adult rural inhabitants varies significantly, not only between individual countries but also between the so-called old (U - 15) and the new (U-13) countries of the EU. 68\% of the rural population of the Western Europe (U-15) has above primary education; whereas, that is the case of almost $83 \%$ of the rural population of the Eastern Europe (U-13). The best educated are the rural inhabitants of the Czech Republic (90.7\% with this level of education); Slovakia (90.5\%) and Estonia (88.7\%). The countries of the Southern Europe are at the opposite end: Portugal (23.9\%), Spain (49.1\%) and Italy (54.6\%). The educational disproportions between the rural and urban areas, which we evaluate very negatively, are observed even more clearly as regards the higher education, which is held by one in ten European rural inhabitants. See data: http://ec.europa.eu/agriculture/agrista/rurdev2010/ RD_Report_2010;table2.2.5.10.

${ }^{5}$ It emerges from Eurostat's latest data that in the EU's countries barely $10 \%$ of adults, i.e. people aged 25-64, undertake further education in the Lifelong Learning system (LLL), with their numbers being considerably lower in the rural areas. See: Learning, Innovation and ICT,. Independent Report. Brussels: ICT cluster with Technopolis and DG Education and Culture of the I European Commission, 2009.

${ }^{6}$ Among others, they are expressed in the article I had written with Anna Pokorska, and which was published in last year's issue of Culture and Education, where we presented the possibilities of e-learning in the process of improving teaching and eliminating educational barriers in Poland's rural areas. See: Pokorska A., and A. Kaleta (2012), 'E-learning in Poland's rural areas', Culture and Education, vol. 3, pp. 119-139.

7 The political confirmation of this thesis can be found in numerous documents of the European Commission and the European Parliament concerning the use of ICT as a supportive tool for the lifelong learning and an evaluation of the results of the activities undertaken by the EU with the purpose of disseminating this type of teaching and learning. They all confirm the usefulness of IT as a development tool of individual and organisational innovations, including e-learning as an instrument of limiting the distances in the field of skills and competences, separating the inhabitants of different countries as well as their urban and rural areas. See: Official Journal of the European Union, Decision no. 1720/2006/EC of the European Parliament and of the Council, "Establishing an action programme in the field of lifelong learning." Brussels: 15 November 2006.; "Better access for rural areas to modern ICT." The European Commission, 2009, Communication from 
down by the first practical experiences analysed in the reports of the Joint Research Centre and the Institute for Prospective Technological Studies affiliated to the European Commission, which show that the support provided by e-learning to general and life education in the workplace and in rural areas is insufficient (Ala-Mutka, Stoyanov). The pace of disseminating this new form of teaching and learning as well as the expected advantages of the rural inhabitants are less spectacular than had been expected and "[...] the initial enthusiasm has been replaced by moderate yet optimistic realism, probably with a greater advantage for both the development of pedagogical principles and practical application of this type of education" (E-learning, p. 21). In order to clarify the causes of this situation, the European Commission set in motion a few international research and development projects during the past few years, the results of which we shall make use of further in this paper.

\section{E-learning - a Diffusion of Innovation}

If we try to explain the introduction of e-learning to the rural areas in categories of the theory of diffusion of innovation - still one of the leading issues in rural sociology - we have a wide social process, being "[...] a particular case of the process of teaching and learning as well as the theory of decision making or general behavioural theory" (Bertrand and Wierzbicki 1970, p. 309). According to its classical model prepared by Everett M. Rogers (Rogers 1960, pp. 399-421), the speed of adaptation of innovation depends on many factors, the first being profitability, which can be partly categorised into economic terms, i.e. the difference between cost and results, and perceived in accordance with the nature of the social system. That primarily means adapting novelties into the system of values and experiences of members of the rural community. Generally, the profitability of innovation grows in communities, which focus on the development, improving the conditions and quality of life; it diminishes in those communities, which have greater appreciation of the achieved status quo and are less mentally prepared for the change.

the 'A new impetus for European Cooperation in Vocational Education and Training' to support the Europe 2020 strategy'. The European Commission, 2010. 
The results of the international research projects of the Euracademy Observatory and E-ruralnet (further: E-ruralnet research) ${ }^{8}$, carried out in 2005-2011 in over a dozen EU countries, including the Institute of Sociology and Torun University in Poland, show that the argument about the growth of the profitability of innovation among people focused on the development gained total confirmation in the surveys on the participants of the courses supported by information technology in the rural areas. For example, of those carried out in 2006 in Poland, i.e. a country in the early phase of the development of this type of education (in comparison with the 15 countries of the so-called old EU), a majority (63\%) of the 106 interviewed inhabitants of the rural areas with such experiences, either had a Master's or a Bachelor's degree. It is symptomatic that the women were in the majority $(64 \% / 60 \%)$ in the countryside and small towns in Poland, being generally better educated than the men. They also dominated in the best educated group of the

${ }^{8}$ Research and development projects:

Euracademy Observatory (A European Observatory of the Use of ICT-supported Lifelong learning by SMEs, Microenterprises and the Self-employed in the Rural Areas the European monitoring of continuous education, assisted by IT, aimed at medium, small and micro enterprises as well as the self-employed in the rural areas) carried out in 2005-2007 in the rural areas of Greece, Finland, Spain, Germany, Poland, Great Britain and Hungary;

Euralnet (Network promoting e-learning for the rural development - A network promoting long distance teaching for the development of the rural areas) carried out in 2009-2011 in the rural areas of Greece, Estonia, Finland, Spain, Germany, Poland, Sweden, Hungary, Great Britain and Italy;

financed by the European Commission within the framework of the Leonardo da Vinci and Lifelong Learning programmes, included among others, extensive empirical research using specially prepared questionnaires, aimed - generally on-line - at institutions offering correspondence courses, participants of such courses (847 respondents in 2006 research, 1737 in 2011 research) and potential participants (respectively 1327 and 1679 respondents) from the rural areas, with the aim of describing the contents of long distance learning in countries participating in the project, identifying existing needs and limitations as well as accessing pan-European comparative data acquired in the researched population.

In the article I refer to the data mentioned in the published research in: A. Kaleta, S. Bieniecka, N. Proń, J. Petrykowska, (2007), The Final Report of the European Union Euracademy Observatory programme - opinions of representatives of teaching institutions, course participants and non- participants, about continuous education, supported by modern information technologies in rural areas, Nicolaus Copernicus University; E-learning in the Rural Context: Innovation, Inclusion and Role of the Market. Report of the Project Results, (2011) Athens. 
respondents: 40 (64\%) were university educated as opposed to $23(54 \%)$ of the men. Such a portrait of the rural e-learning course participants did not generally create problems in providing systematic learning and hence putting into practice one of the most significant conditions for acquiring knowledge and raising qualifications in this way. Almost half (48\%) of the course participants used material available via the Internet three times per week, using both the home computers (around 60\%) and the computers available in school laboratories (80\%). Practically no negative comments were made regarding the standard of the courses on offer. Complaints were made about the technical issues such as interference while accessing the Internet or the speed of transferring the questions during solving of the test. Some of the course participants had problems while studying in the early stages, due to the lack of direct contact with their lecturers (40\%) and other course participants (20\%), i.e. a deeply rooted attachment to the traditional model of education, not however undermining the possibilities offered by the modern telecommunications systems.

The profitability in the case of e-learning does not seem to have much influence on the pace of disseminating this innovation in the rural areas, as their inhabitants - both the e-learning course participants as well as the non-participants - in 2006 and 2011 widely expressed the view that this form of learning has many extensive advantages, including lowering of the costs (see fig. 1).

The social profitability is, therefore, decisive, i.e. there is a lack of fitting into the systems of values and former educational experiences. The research shows that e-learning, as well as other forms of education, do not automatically improve the capacity of coping with the current life problems. The newly acquired knowledge only occasionally leads to finding shortterm work, solving financial problems or enabling contacts with the health service, public administration, the bank or other institutions engulfing us in a dense network, so it is not included in the category of values which are absolutely crucial here and now (see fig. 2).

In addition to the weakness of the mercantile motivations to raise the level of knowledge there is the fear of an unknown form of learning, which is the result of the technological specificity of e-learning, the necessity of using the computer as well as mastering the new technical skills enabling, e.g. the use of the Internet or long distance consultation. 
[11]

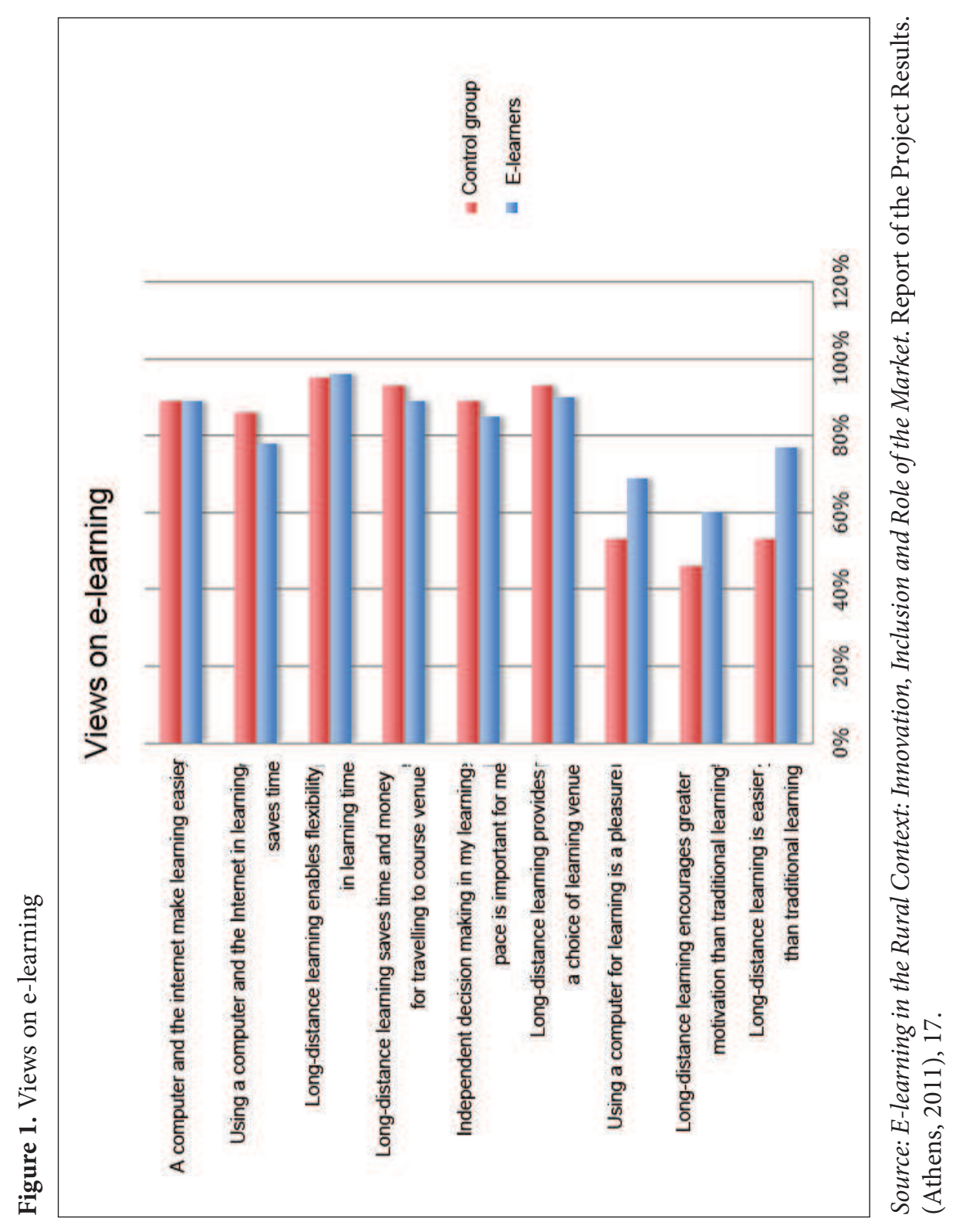


[12]

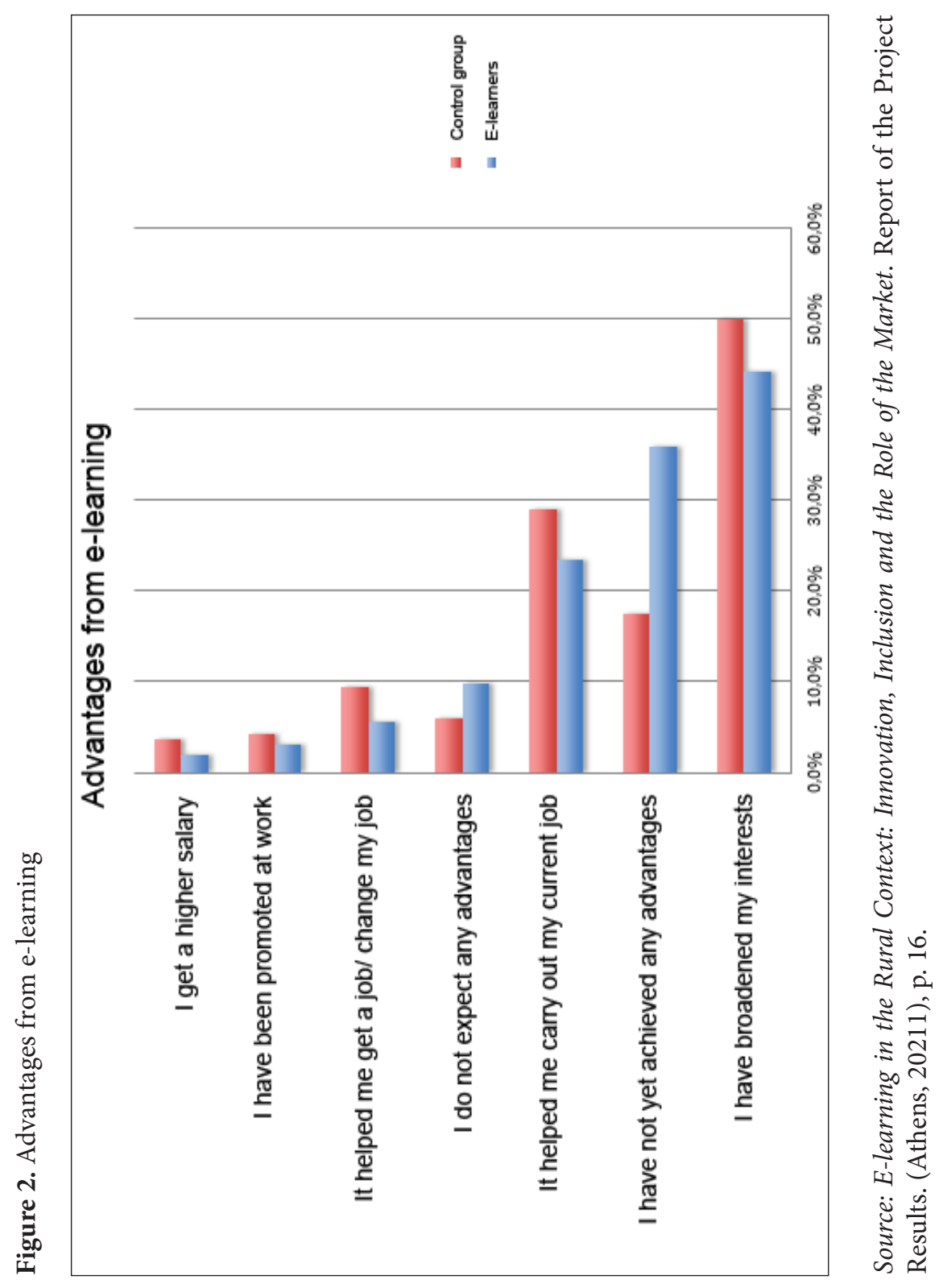


However, both in the light of the E-ruralnet project as in many other papers (Plebańska 2011, pp. 168-171; Penkowska 2010, pp. 49-55) volitional deficits are factors which stand in the way of spreading e-learning, the most frequent being the lack of self-discipline, without which it is difficult for the course participants to function in the independent acquiring of knowledge and responsibility for the results of learning. So the most serious barriers to the dissemination of e-learning in the rural areas are of a mental nature, social personalities which are dominant there: steered from the outside, geared towards copying traditional models of educational and professional careers and a demanding attitude towards educational institutions, including the creators and providers of e-learning.

Due to the generally high costs of preparing and implementing of such courses, only a small number are addressed to the rural inhabitants, i.e. they are prepared taking into consideration both their specific needs and the deficits. The information acquired from the E-ruralnet research from 556 suppliers of e-learning services in $11 \mathrm{EU}$ countries reveals that in every third institution of this kind on the average, the courses are planned and carried out specifically for the rural inhabitants (see fig. 3).

Figure 3. Suppliers focussing on the rural areas

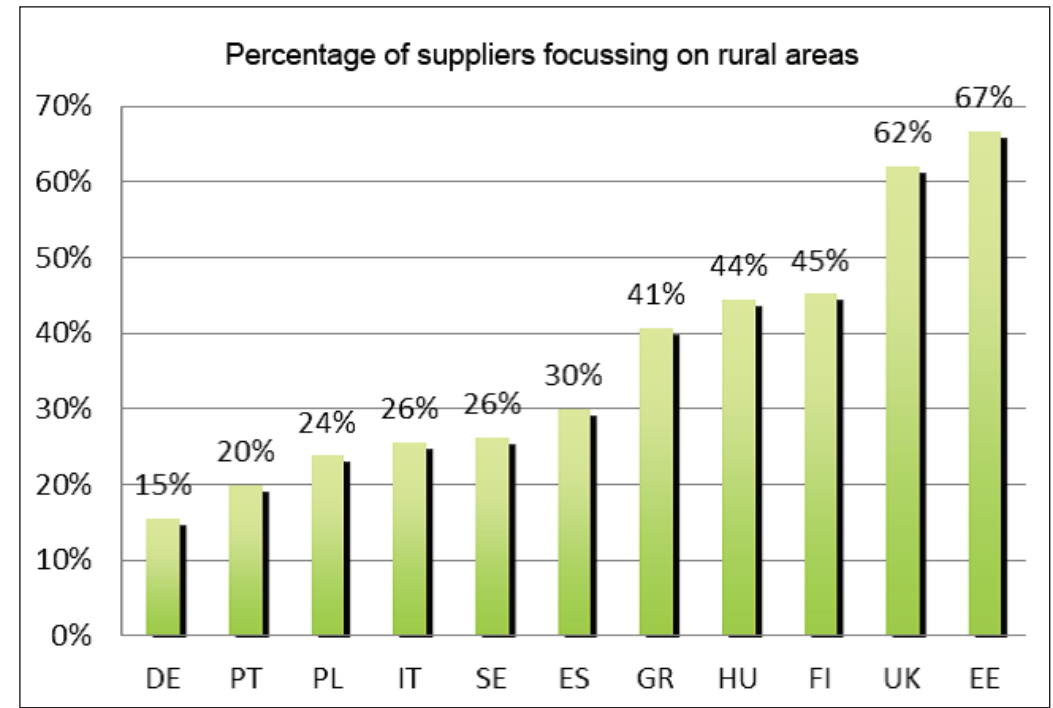

Source: E-learning in the Rural Context: Innovation, Inclusion and the Role of the Market. Report of the Project Results. (Athens, 2011), p. 12. 
There are various reasons for this situation, which differs from country to country (in Germany only $15 \%$ and in Estonia as many as $67 \%$ of the institutions provide specific e-learning courses for the rural areas). There is the lack of broadband access to the Internet, reported by $57 \%$ of the providers (in Greece, Spain and Italy this being the case of over $75 \%$ and in Sweden and Great Britain of $40 \%$ or less). The digital illiteracy is the another cause mentioned by about $50 \%$ of the providers (in Spain and Portugal over $70 \%$ ). In relatively few (about 25\%) of the researched institutions this was explained by the impossibility of financing this type of education by the rural and small town inhabitants (see fig. 4).

Figure 4. Problems with e-learning in rural areas

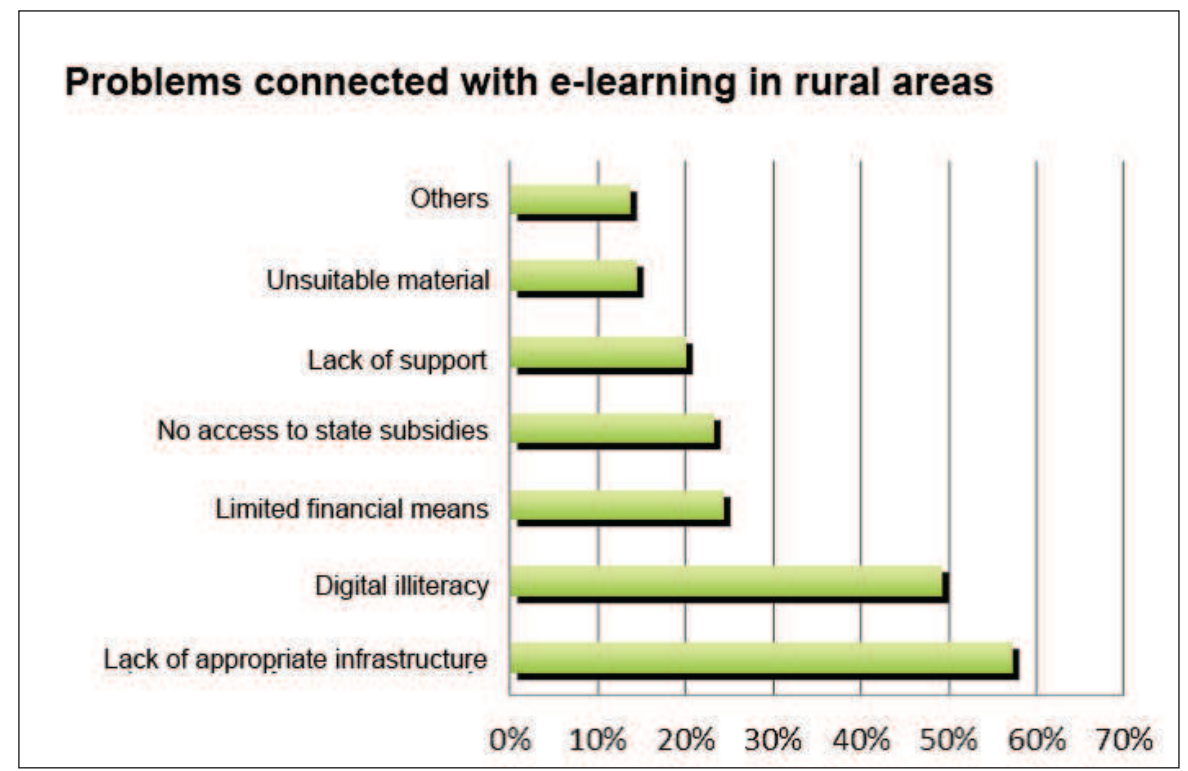

Source: E-learning in the Rural Context, Inclusion and the Role of the Market. Report of the Project Results.(Athens, 2011), p. 12.

\section{Innovative e-learning for the Rural Areas}

Innovative e-learning could serve as the better adaptation of e-learning to the needs of the rural inhabitants by noticing the various types of the deficits 
hindering this form of education, while also accelerating its dissemination in Europe's rural areas. Within the E-ruralnet project, that innovation was defined as the implementation of the new pedagogical solutions, enabling overcoming of the existing restrictions by relaxing the ways of potential students' accessing the e-learning courses and their greater adaptability to the individual requirements. According to the available literature ${ }^{9}$ and professional evaluations carried out for the researchers ${ }^{10}$, a few desiderata were formulated, which should be implemented in this type of education, if it is to become a valid form of Lifelong Learning for a few hundred million of the European rural and small town inhabitants.

The first desideratum is to adjust e-learning to the rural student to a far greater extent than in the past, enabling him/her to work out an individual style and create a personal learning environment as well as integrating the process of acquiring knowledge and skills with his/her professional activity and leisure.

The second desideratum points to the necessity of the e-learning interactivity, i.e. the fixing mechanisms which encourage students to create the virtual communities of learners and activate their members.

If e-learning is indeed to represent the realistic alternative to the conventional education, it should function mainly through the microlearning (the third desideratum); i.e. it should offer small portions of systematic knowledge, stimulating the learner to interact with others; learning in this way, as well as stimulating the context of learning, i.e. their immediate and direct application to solving his/her real life problems.

9 Among others: Atton, C. (2002), Alternative Media, London; Attewell, J. (2005), Mobile Technologies and learning. ATechnology Update and e-Learning Project Summary, London; Warren, M. (2007), 'The digital vicious cycle: Links between social disadvantage and digital exclusion in rural areas', Telecommunications Policy, vol. 31 (6-7); Crosta, L. and V. Prieto, (2009) 'How to measure innovation in e-Learning: The i-AFIEL methodology." E-Learning Papers, vol. 13, available at: www.elearning papers.eu.; an extensive bibliography concerning the innovation in e-learning is available at: http://www.prismanet.gr/eruralnet/ en/innovative_e-learning.php.

${ }^{10}$ L. Laschewski, Innovative e-Learning in Rural Areas. [Online] Available: http:// www.prismanet.gr/eruralnet/en/innovative e-learning.php.; D.Rove, Alternative Media and Contemporary Applications of e-learning in a Rural Context. [Online]. Available: http:// www.prismanet.gr/eruralnet/en/alternative_media.php. 
The fourth desideratum was described as the interoperation of e-learning, i.e. the necessity of working out technical standards for the rural areas, enabling the use of such education regardless of the type of the network, equipment or computer programme, as well as creating the possibilities of using the mobile telephone, i-pods etc., the free programme access and recycling older forms of the computers handed over for the educational purposes by the industrial and services sector. This is the basic condition for the economic effectiveness of e-learning because it means lowering the learning costs.

And finally, the fifth desideratum, e-learning requires the implementation of procedures for managing the quality and evaluation, demanding that the providers of such services react promptly to the users' needs, satisfying them by maintaining the high teaching standards, managing the process of learning and their constant evaluation, including the evaluation of the students' results through the implementation of the systems assuring the validation of skills and their certification (E-learning, p. 22).

\section{Instead of the Summary}

It clearly emerges from the presented material that although the education aided by IT, above all e-learning, opens the variety of largely undisputed possibilities of the access to knowledge, further efforts are required in order to disseminate these solutions.

In the first decade of the $21^{\text {st }}$ century, the infrastructural problems have been solved to a greater or lesser extent, largely due to the EU's policy promoting the idea of society based on knowledge. Although the technical installations necessary for its materialisation in the rural areas through the implementation of e-learning are not cheap, it has been possible to practically eliminate the barrier in the access to the computer equipment and the network, due to the partnership between the public and private resources. Mercantile aspects were significant, and hence hopes for the profit largely from telecommunications operators, who assumed that the traditional systems of disseminating knowledge would be unable to compete with those supported by ICT as regards the comfort, versatility, ways of preparing the content and, above all, the cost of teaching and learning. The intermediary confirmation of the farsightedness of such reasoning are the numerous enterprises and institutions emerging in Europe and dealing with 
the creation of the technical equipment, academic aids and the preparation of the content of education for e-learning, sometimes connected with the powerful electronic industry and the mass media market. ${ }^{11}$ The investments in the communications infrastructure have not solved the problem of the digital exclusion in the rural areas, being to an ever diminishing extent the result of the technological barriers (now restricted to the broadband access) and with the decisive result of the deficit of the digital competence (the digital illiteracy) of mainly the older generation living there (Laschewski 2008).

The second and possibly third decade of the $21^{\text {st }}$ century raises the far more difficult challenge of providing e-learning to the remotest areas, and this cannot be done by simply transferring money into the development of the communications systems and free access to the computer equipment and the Internet. This entails the necessity of the activities encouraging the participation in the life-long learning by using this form of education. It has already been pointed out that the realisation of both of these goals requires the fundamental technological innovation which is methodical and organisational in the learning environment. This also requires the programmes and activities animating the rural communities, aimed on the one hand at overcoming mental deficits, and on the other, the closer connection of knowledge with satisfying more basic needs such as the job opportunities. In other words, it is a question of working out the new learning culture focussing on the individual and his/her real needs.

However, the animation is a complex and long-term social process, more complicated and less predictable as regards achieving the set goals than the investment in the infrastructure. It is more difficult to find the good animators than the computer specialists, as it is more difficult to acquire the funding for the animation activity from both of the state sources, not to mention the private ones.

\section{References}

Ala-Mutka, K., (2010), Learning in Informal Networks and Communities. JRC-IPTS Technical Report Series. Luxembourg: the European Commission.

\footnotetext{
11 In E-ruralnet research even in the countries such as Poland or Greece (in the early phases of the e-learning development) a few hundred initiatives of this type were identified; whereas, in Germany or Great Britain several dozen thousands were identified.
} 
Bertrand, A. L., and Z. T. Wierzbicki (1970), Socjologia wsi w Stanach Zjednoczonych. Stan i tendencjerozwojowe [The Rural Sociology in the USA. The State and development tendencies]. Wroclaw-Warsaw-Krakow.

E-learning in the Rural Context: Innovation, Inclusion and the Role of the Market. (2011), Report of the Project Results. Athens.

Laschewski, L. (2008), 'Boundless Opportunities? Visions and Setbacks to Digital Learning in Rural Areas', Eastern European Countryside, vol. 14.

Rogers, E. M. (1960), Social Change in Rural Society, New York.

Penkowska, G. (2010), Meandry e-learningu [The Meanders of e-learning], Warszawa.

Plebańska, M. (2011), E-learning. Tajniki edukacji na odległość [E-learning. The secrets of the distance education], Warszawa.

Soyanov, S., B. Hoogveld and, P. Kirschner, (2010), Mapping Major Changes to Education and Training in 2025, JRC-IPTS Technical Report Series. Luxembourg: the European Commission. 